\title{
Mineral content of the forearms of babies born to Asian and white mothers
}

\author{
P CONGDON, A HORSMAN, P A KIRBY, J DIBBLE, T BASHIR
}

\begin{abstract}
Vitamin $D$ deficiency is common in pregnant Asian women. The effect of maternal vitamin $D$ deficiency on fetal skeletal mineralisation was assessed by measuring the bone mineral content of babies born to 45 Asian women, 19 Asian women who had received 1000 units of vitamin $D$ during the last trimester, and 12 white women. The mean cord blood concentrations of 25-hydroxy vitamin $D$ in the three groups were $5.9 \pm S E 0.9 \mathrm{nmol} / 1$ (2.4 SE 0.4 ng/ml), 15.2 $\pm 3.2 \mathrm{nmol} / 1(6.1 \pm 1.3 \mathrm{ng} / \mathrm{ml})$, and $33.4 \pm 3.6 \mathrm{nmol} / 1(13.4 \pm 1.4 \mathrm{ng} / \mathrm{ml})$, respectively. Despite this wide variation in values there was no significant difference in the bone mineral content (as assessed by photon absorptiometry) of the forearms of babies born to these women. This suggests that mineralisation of the fetal skeleton is not impaired in maternal vitamin $D$ deficiency.

Craniotabes (skull softening) was present in seven of the 64 Asian babies. The bone mineral content in these babies was not significantly different from that of babies without this sign, and craniotabes should not therefore be taken as an indication of a generalised impairment in skeletal mineralisation.
\end{abstract}

\section{Introduction}

The need of the growing fetus for calcium presents a major strain on maternal calcium homoeostasis. This fetal demand is satisfied in vitamin $\mathrm{D}$ replete pregnant women by enhanced intestinal absorption of calcium brought about by increased concentrations of 1,25-dihydroxy vitamin D. ${ }^{1}$

\footnotetext{
General Infirmary, Leeds LS1 3EX, and MRC Mineral Metabolism Unit

P CONGDON, MRCP, DCH, consultant paediatrician

A HORSMAN, BA, PHD, MRC Mineral Metabolism Unit

P A KIRBY, MRC Mineral Metabolism Unit

St James's University Hospital, Leeds LS9 7TF

J DIBBLE, MB, MRCP, senior registrar in medicine

$T$ BASHIR, MB, MRCOG, lecturer in obstetrics

Correspondence to: Dr P Congdon.
}

Some studies suggest that maternal malnutrition impairs fetal skeletal mineralisation. ${ }^{2}$ Babies born to Asian mothers deficient in vitamin $D$ tend to have higher alkaline phosphatase activities and larger anterior fontanelles than babies born to vitamin $\mathrm{D}$ replete mothers, suggesting some impairment in fetal skeletal ossification. $^{3}$

Pregnant Asian women living in Britain are commonly deficient in vitamin $\mathrm{D}^{3}{ }^{4}$ We studied the effect that vitamin $\mathrm{D}$ deficiency may have on skeletal mineralisation in the fetus by assessing bone mineral content of the forearm of babies born to Asians deficient in vitamin $\mathrm{D}$, Asians supplemented with vitamin $\mathrm{D}$ during pregnancy, and white women with normal vitamin $\mathrm{D}$ concentrations. Bone mineral content was measured by photon absorptiometry, which is accepted as an accurate and precise technique both in adults ${ }^{5}$ and in neonates. ${ }^{6}$ ?

The study was approved by the hospital ethical committee and consent for the investigations obtained from mothers before the bone scans.

\section{Patients and methods}

Cord blood was collected at term (37-42 weeks) from 45 Asian women who had received no vitamin D supplements (group 1), from 19 Asians who had received 1000 units of vitamin D daily (calcium with vitamin $\mathrm{D}$ tablets $B P C$ ) during the last trimester of pregnancy (group 2), and from 12 white women (group 3). Samples were separated and stored at $-20^{\circ} \mathrm{C}$ and plasma 25 -hydroxy vitamin D concentrations measured in duplicate by competitive protein binding assay after preliminary extraction and chromatography. ${ }^{8}$

Calcium, phosphorus, albumin, and alkaline phosphatase values (Asian babies only) were measured by a Technicon SMA Plus autoanalyser.

The bone mineral content of the right forearm of babies born to these women was measured within the first five days, usually within 48 hours. The forearm was placed in a thin rubber sleeve surrounded by water and scanned midway between the wrist and the elbow with a narrow beam of radiation from an americium-241 source. In every case two scans were performed, taking a total of five minutes. The radiation dose per scan was less than $0.2 \mathrm{mrem}$. Radiation transmitted through the forearm was measured using a scintillation counter detector. Counts were stored in a pulse height analyser (multiscaling mode). Bone mineral content was evaluated from the scan data and the mean of the two results used in the subsequent analysis. Results were expressed in arbitrary units proportional to the mineral mass per unit length of the radius and ulna combined.

At the time of the scan we noted whether craniotabes was present. 


\section{Results}

Mothers and infants (table I)-There was no significant difference between the three groups in maternal age, gestational age, ratio of boys to girls, or the proportion of infants born with craniotabes. The mean birth weight of babies born to the non-supplemented Asian women was $3056 \pm \mathrm{SE} 59 \mathrm{~g}$, of those born to supplemented Asian mothers $3173 \pm 108 \mathrm{~g}$, and of babies born to the white women $3223 \pm 195$ g. Although there was a tendency for babies born to non-supplemented Asian mothers to be lighter, the three mean values did not differ significantly from one another.

Biochemical results (table II)-Cord blood concentrations of 25hydroxy vitamin $\mathrm{D}$ were significantly higher $(\mathrm{p}<0.001)$ for women in group 3 (mean 33.4 SE $3.6 \mathrm{nmol} / 1 ; 13.4+\mathrm{SE} 1.4 \mathrm{ng} / \mathrm{ml}$ ) than for women in group 2 (mean $15.2 \pm 3.2 \mathrm{nmol} / 1 ; 6.1 \pm 1.3 \mathrm{ng} / \mathrm{ml}$ ) and group 1 (mean $5.9+0.9 \mathrm{nmol} / 1 ; 2.4+0.4 \mathrm{ng} / \mathrm{ml}$ ). Forty one of the unsupplemented Asian mothers $(91 \%)$ as compared with 11 of the supplemented group $(58 \%)$ had concentrations below $10 \mathrm{nmol} / 1$ $(4.0 \mathrm{ng} / \mathrm{ml})$. No white woman had a value below $10 \mathrm{nmol} / \mathrm{l}$. Failure to raise the vitamin $\mathrm{D}$ concentration (into the normal range) in a few women who were given vitamin $\mathrm{D}$ supplements may have been due to non-compliance, since other workers have found that 1000 units daily results in increased plasma concentrations of 25 -hydroxy vitamin D in most cases. ${ }^{3}$

Seven of the 64 babies had craniotabes, but there was no association between the presence of skull softening and the plasma vitamin $\mathrm{D}$ value.

The mean plasma calcium concentration was significantly higher in the supplemented Asian group than in the non-supplemented Asians $(p<0.025)$ but there was no significant difference between the two Asian groups in albumin, phosphorus, or alkaline phosphatase values.

Bone mineral content at birth for all Asian babies was significantly related to birth weight $(\mathrm{r}=0.46 ; \mathrm{p}<0.001)$ but not to parity or maternal age. There was no significant correlation between bone mineral content and the cord blood 25-hydroxy vitamin D concentration in Asians. Although the mean mineral content was higher in babies born to group 2 mothers than in those born to group 1 mothers, this difference was not significant. Similarly the bone mineral content was no greater for white babies than for babies born to either supplemented or unsupplemented Asian mothers. There was no significant correlation between the bone mineral content and vitamin D concentration for Asian and white babies combined.

The observations in groups 1 and 2 were pooled and the 20 Asian babies with the highest cord blood concentrations (mean 19.0 \pm 2.8 $\mathrm{nmol} / 1 ; 7 \cdot 6+1 \cdot 1 \mathrm{ng} / \mathrm{ml}$ ) were compared with the 20 babies with the lowest values (mean $2 \cdot 1 \pm 0.3 \mathrm{nmol} / 1 ; 0.9 \pm 0.1 \mathrm{ng} / \mathrm{ml}$ ). The bone mineral content in the first group was slightly greater than in the second group (3.4 $+0 \cdot 1$ and $3 \cdot 2+0 \cdot 1$ units, respectively), but this difference was not significant.

There was no significant association between the bone mineral content and the presence or absence of craniotabes.

TABLE I-Clinical details of mothers and infants born to Asian and white women $M e a n$ values expressed $\pm S E$

\begin{tabular}{lccc}
\hline & \multicolumn{2}{c}{ Asian babies } & White babies \\
\cline { 2 - 3 } & $\begin{array}{c}\text { Non-supplemented } \\
\text { (group 1) }\end{array}$ & $\begin{array}{c}\text { Supplemented } \\
\text { (group 2) }\end{array}$ & \\
\hline Maternal age (years) & $27 \cdot 18 \pm 1 \cdot 03$ & $27 \cdot 63 \pm 1 \cdot 70$ & $26 \cdot 20 \pm 1 \cdot 40$ \\
Birth weight (g) & $3056 \pm 59$ & $3173 \pm 108$ & $3223 \pm 195$ \\
Gestation (weeks) & $39 \cdot 16 \pm 0 \cdot 17$ & $39 \cdot 20 \pm 0.20$ & $39 \cdot 00 \pm 0 \cdot 40$ \\
Boys:girls & $20: 25$ & $9: 10$ & $7: 5$ \\
No with craniotabes & 3 & 4 & 0 \\
\hline
\end{tabular}

TABLE II-Results of biochemical measurements on cord plasma samples, and bone mineral content measurements. Mean values expressed $\pm S E$

\begin{tabular}{|c|c|c|c|}
\hline & \multicolumn{2}{|c|}{ Asian babies } & \multirow{2}{*}{$\begin{array}{l}\text { White babies } \\
\text { (group 3) }\end{array}$} \\
\hline & $\begin{array}{l}\text { Non-supplemented } \\
\text { (group 1) }\end{array}$ & $\begin{array}{l}\text { Supplemented } \\
\text { (group 2) }\end{array}$ & \\
\hline Calcium $(\mathrm{mmol} / \mathrm{l})$ & $2.50 \pm 0.03$ & $2 \cdot 64: 0.05$ & \\
\hline $\begin{array}{l}\text { Phosphorus (mmol/l) } \\
\text { Alkaline phosphatase }\end{array}$ & $1.64 \pm 0.05$ & $1.69+0.06$ & \\
\hline $\begin{array}{l}\text { (KA units) } \\
\text { Albumin }(\mathrm{g} / 1)\end{array}$ & $\begin{array}{l}13.63 \div 0.62 \\
38.84 \div 0.57\end{array}$ & $\begin{array}{l}13.43 \div 1.03 \\
39.63 \div 0.94\end{array}$ & \\
\hline $\begin{array}{l}\text { 25-Hydroxy vitamin D } \\
(\mathrm{nmol} / \mathrm{l})\end{array}$ & $5.90 \div 0.93$ & $15 \cdot 20 \div 3 \cdot 15$ & $33.40: 3.60$ \\
\hline $\begin{array}{c}\text { Bone mineral content } \\
\quad(\text { arbitrary units)** }\end{array}$ & $3 \cdot 10 \div 0 \cdot 10$ & $3 \cdot 19: 0.12$ & $2.94+0.19$ \\
\hline
\end{tabular}

\section{* See text.}

Conversion: SI to traditional units-Calcium: $1 \mathrm{mmol} / 1 \approx 4 \mathrm{mg} / 100 \mathrm{ml}$. Phosphorus
$1 \mathrm{mmol} / 1 \approx 3 \mathrm{mg} / 100 \mathrm{ml}$. 25 -Hydroxy vitamin $\mathrm{D}: 1 \mathrm{nmol} / 1 \approx 0.4 \mathrm{ng} / \mathrm{ml}$.

\section{Discussion}

The fetal requirement for calcium increases progressively $\stackrel{\mathbb{Q}}{\complement}$ during pregnancy and represents an appreciable strain on maternal calcium homoeostasis. The total calcium content of a $\cong$ $3500 \mathrm{~g}$ baby is about $28 \mathrm{~g}$, of which $98^{\circ} \%$ is present in the skeleton. ${ }^{9}$ Fetal calcium accretion rates rise progressively from $\mathbb{\infty}$ some $2-3 \mathrm{mg}$ a day in the first trimester to $250 \mathrm{mg}$ a day at 37-40 weeks. ${ }^{10}$ This fetal demand for calcium in the last weeks $\varrho$ of pregnancy is equivalent to about one fifth of the recommended maternal calcium intake $(1200 \mathrm{mg} \text { daily })^{11}$ at that time. The $\stackrel{0}{+}$ mechanism by which this progressive demand by the fetus for 0 calcium is satisfied in vitamin $\mathrm{D}$ replete women appears to be enhanced intestinal absorption of calcium in the mother. ${ }^{1}$

It is not clear how this fetal demand for calcium can be $\mathbb{\mathbb { D }}$ satisfied in mothers deficient in vitamin D. Although the diet of many Asian women in Britain is deficient in calcium, ${ }^{12}$ it is possible that calcium absorption and utilisation may be more efficient than in those who are accustomed to higher intakes. ${ }^{13} \overrightarrow{\vec{\omega}}$ Balance studies in Asians with calcium intakes of about $400 \mathrm{mg} \stackrel{\omega}{\omega}$ daily have shown increasing retention throughout pregnancy, $\frac{O}{3}$ being greatest during the last trimester when fetal accretion rate is maximal. ${ }^{14}$ Although this is in part due to a reduction in $\infty$ faecal calcium losses, there is also a concomitant reduction in urinary calcium excretion. ${ }^{14}$ This latter effect may be mediated $\omega$ by raised parathyroid hormone concentrations, ${ }^{15}$ though the $\omega$ evidence for relative hyperparathyroidism during pregnancy is $\vec{N}$ conflicting. ${ }^{1} 16$

Studies in rats point to a vitamin $\mathrm{D}$ independent mechanism $\mathrm{O}$ which promotes both increased intestinal absorption of calcium $\vec{\nabla}$ and mobilisation of calcium from bone. ${ }^{17}$ The mechanism for $\sigma$ this is not clear, but the total body calcium of fetuses was not related to the vitamin $\mathrm{D}$ state of the mother. ${ }^{17}$

As Asian resicients in Britain are commonly deficient in $\vec{\emptyset}$ vitamin $\mathrm{D}$, and because calcium transported across the placenta $\omega$ is primarily deposited in the fetal skeleton, an assessment of the bone mineral content in newborn babies of these women should indicate whether a lack of vitamin D impairs accretion of calcium by the fetus. Sustained plasma 25-hydroxy vitamin D concentrations below $10 \mathrm{nmol} / 1(4 \mathrm{ng} / \mathrm{ml})$ are associated with osteo- $\mathbb{D}$ malacia, ${ }^{3}$ and in our study 41 out of 45 unsupplemented Asians and 11 out of 19 supplemented Asians had cord blood concentrations below that value. Previous studies ${ }^{18}$ have shown a very strong correlation between maternal and cord blood concentrations of 25-hydroxy vitamin D.

We found no significant reduction in the bone mineral content of babies born to vitamin $\mathrm{D}$ deficient Asian women compared with babies born to vitamin D replete white mothers. Although the bone mineral content of babies born to Asians who had $\frac{3}{6}$. received vitamin $D$ supplements was slightly higher than for $\delta$ those born to vitamin $\mathrm{D}$ deficient Asians, this difference was not $₹$ significant. Comparing all Asian with white babies also failed to윽 show a relation between the bone mineral content and vitamin $D_{N}$ values. In keeping with these findings, the bone mineral content of babies born with craniotabes was not significantly lower than in those without this sign. Skull softening in Asians is probably not a reflection of generalised defective skeletal mineralisation. We did not try to assess changes in maternal skeletal mineralis- $\omega$ ation, so we cannot say whether the fetal skeletal requirement? for calcium was satisfied at the expense of the maternal skeletone or as a result of decreased urinary and faecal calcium excretion.

Our results therefore seem to indicate that the fetal demand? for calcium can be satisfied even when the mother is deficient in $\frac{0}{T}$ vitamin $\mathrm{D}$, and the relative rarity of congenital rickets in Asians $\frac{\overrightarrow{\mathrm{D}}}{\mathrm{D}}$ supports our conclusion that maternal vitamin $\mathrm{D}$ deficiency does $\stackrel{?}{?}$ not usually result in defective mineralisation of the fetal skeleton. $\stackrel{\unrhd}{\unrhd}$ Despite our findings there remain good reasons for trying to improve the vitamin D state in pregnant Asian women. Previous 0 studies have shown an increased tendency for their babies to음 develop hypocalcaemia ${ }^{3}$ and to be of low birth weight. ${ }^{3}$ The long term effects that vitamin $\mathrm{D}$ deficiency has on growth and dentition need careful study. Non-compliance because of 
language problems is likely to be a major obstacle if supplementation is given as tablets.

\section{References}

1 Whitehead $M$, Lane $\mathrm{G}$, Young $\mathrm{O}$, et al. Interrelation of calcium regulating hormones during pregnancy. $\mathrm{Br}$ Med $\mathcal{f} 1981 ; 283$ :10-2

${ }^{2}$ Krishnamachari K, Iyengar L. Effect of maternal malnutrition on the bone density of the neonate. Am F Clin Nutr 1975;28:482-6.

${ }^{3}$ Brook OG, Brown IRF, Bone CDM, et al. Vitamin D supplements in pregnant Asian women: effects on calcium state and fetal growth. Br Med 7 1980;280:751-4.

${ }^{4}$ Heckmatt JZ, Peacock M, Davies AEJ, et al. Plasma 25-hydroxy-vitamin $\mathrm{D}$ in pregnant Asian women and their babies. Lancet 1979;ii:546-9.

${ }^{6}$ Cameron JR, Sorenson J. Measurement of bone mineral in vivo: an improved method. Science 1963;142:230-2.

${ }^{6}$ Minton SD, Steichen JJ, Tsang RC. Bone mineral content in term and preterm appropriate for gestational age infants. $\mathcal{F}$ Pediatr 1979;95: 1037-42.

7 Roberts CC, Chan GM, Folland D, et al. Adequate bone mineralisation in breast-fed infants. $\mathcal{F}$ Pediatr $1981 ; 99: 192-6$.

${ }^{8}$ Skinner RK, Willis MR. Serum 25-hydroxy-vitamin D assay. Evaluation of chromatographic and non-chromatographic procedures. Clin Chim Acta $1977 ; 80: 543-54$.
${ }^{9}$ Forfar JO. Normal and abnormal calcium, phosphorus and magnesium metabolism in the perinatal period. Clin Endocrinol Metab 1976;5: 123-48.

${ }^{10}$ Cundy T, Kanis JA. Calcium homoeostasis during pregnancy. $\mathrm{Br}$ Med $\mathcal{f}$ $1981 ; 283: 562-3$.

11 Department of Health and Social Security. Recommended intake of nutrients for the United Kingdom. London: HMSO, 1969. (Reports on Public Health and Medical Subjects. No 120.)

12 Watney PJM, Chance GW, Scott P, Thompson JM. Maternal factors in neonatal hypocalcaemia: a study in three ethnic groups. Br Med $\mathcal{F} 1971$ ii :432-6.

${ }^{13}$ Widdowson EM, Dickerson JWT. In: Comar CL, Bonner F, eds. Mineral metabolism. Vol 2. New York: Academic Press, 1964.

${ }^{14}$ Shenolikar IS. Absorption of dietary calcium in pregnancy. Am $\mathcal{F}$ Clin Nutr 1970;23:342-4.

15 Heaney RP, Skillman TG. Calcium metabolism in normal human pregnancy. F Clin Endocrinol Metab $1971 ; 33: 661-70$.

16 Cushard WG, Creditor MA, Canterbury JM, Reiss E. Physiologic hyperparathyroidism in pregnancy. F Clin Endocrinol Metab 1972;34:767-71.

17 DeLuca HF. Some new concepts emanating from a study of the metabolism and function of vitamin D. Nutr Rev 1980;38:169-82.

18 Hillman LS, Haddad JG. Human perinatal vitamin D metabolism: 25 hydroxy-vitamin D in maternal and cord blood. $\mathcal{F}$ Pediatr $1974 ; 84: 742-9$.

\title{
Effect of environment on blood pressure: home versus hospital
}

\author{
M A YOUNG, D B ROWLANDS, T J STALLARD, R D S WATSON, W A LITTLER
}

\begin{abstract}
The effect of environment on blood pressure was studied by recording intra-arterial pressure continuously in nine patients with essential hypertension during controlled periods of activity and rest at home and in hospital. Mean systolic pressure was higher at home $(152 \pm 16 \mathrm{~mm} \mathrm{Hg})$ than in hospital $(138 \pm 11 \mathrm{~mm} \mathrm{Hg}$, $p<0.01)$, the difference being greatest during the period of activity (165 $21 v 142 \pm 13 \mathrm{~mm} \mathrm{Hg}, p<0.001)$; heart rates and diastolic pressures did not differ significantly at these times. Systolic pressure recorded by conventional sphygmomanometry was also higher at home $(173 \pm 23 v$ $159.23 \mathrm{~mm} \mathrm{Hg}, \mathrm{p}<0.01)$, as was diastolic pressure (98 10 v $89+11 \mathrm{~mm} \mathrm{Hg}, \mathbf{p}<0.02)$.

Systolic pressure was consistently higher at home, and this effect was independent of the presence of an observer. This must be taken into consideration when assessing blood pressure and efficacy of treatment in hospital.
\end{abstract}

\section{Introduction}

The decision to initiate lifelong treatment in a hypertensive patient is usually made in hospital, a hospital outpatient clinic, or a general practitioner's surgery. How well each of these environments reflects a patient's day to day blood pressure, however, remains speculative. To gain an idea of the true day to day pressure it is necessary to observe the patient in as

\footnotetext{
Department of Cardiovascular Medicine, East Birmingham Hospital and University of Birmingham

M A YOUNG, MRCP, honorary registrar

D B ROWLANDS, MRCP, honorary registrar

T J STALLARD, AIMLT, senior scientific officer

R D S WATSON, MD, MRCP, senior registrar

W A LITTLER, MD, FRCP, professor

Correspondence to: Dr M A Young.
}

many environments as possible, and it is also necessary to standardise those factors that affect moment to moment changes in blood pressure. ${ }^{1}$ Furthermore, the influence of observer interaction has been emphasised in the past, at times raising systolic pressure by as much as $45 \mathrm{~mm} \mathrm{Hg} .{ }^{2}$ We therefore designed this study to clarify the effects of the home and hospital environments on blood pressure during strictly controlled conditions of activity and rest and in the presence and absence of an observer.

\section{Patients and methods}

We studied nine patients (six men) aged 22-62 (mean age 45) diagnosed as having essential hypertension on the basis of three separate outpatient standard cuff pressures of at least $140 / 90 \mathrm{~mm} \mathrm{Hg}$. Korotkoff phase $\mathrm{V}$ was taken as diastolic pressure. Patients had no evidence of target organ damage, and secondary hypertension was excluded by clinical examination, estimation of urea, electrolyte, and creatinine concentrations, and intravenous pyelography when appropriate. Patients were untreated for at least three months before admission, and all gave informed consent.

Outpatient pressures were measured using a standard mercury sphygmomanometer; patients generally rested supine for about five minutes before their pressures were measured. After admission to hospital in the afternoon each patient was randomised to spend the first of the next two days either at home or in hospital. Five patients were randomised to spend the first day at home (mean age of group 44.6 years; three men; mean outpatient pressure 161/ $95 \mathrm{~mm} \mathrm{Hg}$ ) and four to spend the first day in hospital (mean age of group 44.7 years; three men; mean outpatient pressure $165 / 92 \mathrm{~mm} \mathrm{Hg}$ ). The following morning a Teflon cannula $1 \mathrm{~mm}$ in diameter was introduced percutaneously into the left brachial artery and intraarterial blood pressure recorded continuously on to a portable analogue recorder. ${ }^{3}$ The tape was analysed beat to beat by computer after periods of damping or artefact had been excluded. ${ }^{4}$

After cannulation at $9 \mathrm{am}$ patients were allowed to settle and familiarise themselves with wearing the equipment; they were also given diary cards to record their activities. At 11 am, depending on randomisation, the patient either was driven home or remained in hospital. Between 12 noon and 1 pm patients were told to have lunch. They were instructed to rest supine from $1 \mathrm{pm}$ to $2 \mathrm{pm}$ and 